\title{
Do doctors owe a special duty of beneficence to their patients?
}

\author{
Raanan Gillon Imperial College of Science and Technology, London University
}

The continuing debate in these pages about whether or not doctors are among those groups in society who have special, supererogatory moral obligations to their clientele seems important enough to pursue, even at the acknowledged risk of boring some readers. In this issue Professor Downie furthers the discussion by arguing against three claims defended in a previous editorial (1). Those claims were:

(a) that a doctor has a special professional obligation to benefit his patients medically;

(b) that that obligation is at least in part altruistic in that it is self-imposed by the medical profession not to benefit themselves but to benefit their patients;

(c) that it is at least in part supererogatory in that it goes beyond what is required of every person and every occupation.

Downie denies (a), saying that other groups - for example pilots and shopkeepers - have special obligations to their clients. To say that doctors have special obligations is not to make a moral point at all but simply to define what it is to be a doctor'. He argues that (b) 'is either trivially true or plain false'. And while being ready to concede that some individual doctors go beyond what is required by the ordinary moral requirements that apply to us all, Downie rejects (c) because he cannot accept that supererogation is a characteristic of the role of the doctor as such - that supererogation is part of the concept of 'doctor' (in the sense of medical practitioner).

There are two parts of Downie's riposte to (a). The first part states that other groups have special obligations to their clientele and gives as examples pilots and shopkeepers. Even if this counterclaim were conceded it is important to realise that the claim at stake was not that only doctors had special moral obligations of beneficence to their clients - only that doctors do have such obligations. To overturn that claim by examples it would be necessary to show that most or all occupations had at least as much obligation of beneficence to their clients as doctors have to theirs. One or two examples could not suffice. However, it seems fairly clear that even the two examples chosen by Downie do not support his position for neither shopkeepers nor pilots have special moral obligations of beneficence to their clients, in addition to the standard moral obligations we all owe each other, whatever our occupations. Perhaps the best evidence ? for this is that it seems highly improbable that members of these groups would claim themselves to have any such special moral obligations of beneficence 윽 to their clients and equally improbable that they would be widely recognised by others as having any such obligations.

The second part of Downie's riposte to (a) is that to say that doctors have special obligations to their patients which non-doctors do not have 'is not to make a moral point at all but simply to define what is to be a doctor'. Well of course all different occupations can be differentiated from each other in terms of the specia obligations of their practitioners: the pilot has a obligation to his customer to fly him from one place to another, the butcher to carve and supply a piece of fillet when he has agreed to do so, the copy typist to produce a well-typed version of the material he has undertaken to type. It is, furthermore, often perhaps even usually the case that clients who have voluntarily paid for services or goods are likely to want them and thus at least prima facie likely to benefit from them. The point of the claim defended in (a) is that in many, perhaps most, occupations it would be entirely legitimate for 0 the supplier of the services concerned to be totally uninterested in whether or not the services or goods he supplies are of benefit to the client. If the client wants the goods or services and is prepared to pay for them then there is no moral obligation in many (though by no means all) occupations for the supplier to be concerned about whether or not the services or goods will as a matter of fact be of benefit to the recipient. In os medicine on the other hand there is such an obligation. $N$ While respect for the patient's autonomy is a vital part స్ట of medical ethics, and while it is usually the case that $\bar{O}$ the patient's informed desires are the best indication of what will be beneficial for that patient, none the less a doctor is morally obliged not to do things to his patients $\stackrel{\oplus}{\rightarrow}$ unless he intends and reasonably expects to benefit $\square$ them. While a butcher for example can reasonably and 0

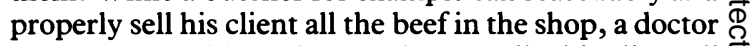
cannot reasonably and properly prescribe his client all $\stackrel{\mathbb{Q}}{\varnothing}$ the penicillin or even the aspirin (let alone the $\frac{\varrho}{\sigma}$ morphine) in the shop even if the client is quite clear 
that he wants it and will pay for it and even if, as in the case of the aspirin, the patient can go and buy it without a prescription.

More generally the reply to this counterargument of Downie's is that while members of all occupations have to respect the normal prima facie moral obligations we all have of respecting other people's autonomy, of keeping our promises including our contracts, of honesty, of obeying (just) laws, and of avoiding intentionally harming others, only some occupations have a moral obligation to act with the intention of benefiting their clients and not to act unless that intention can reasonably be expected to be fulfilled. That obligation is by definition an obligation of beneficence. Doctors - and perhaps the health-care professions in general - have this moral obligation of beneficence to their patients. Because many occupational groups do not have it, it is reasonable to call it a special obligation of beneficence to their patients. Because it is a moral obligation such that doctors ought to act with the intention and reasonable anticipation of benefiting their patients, and may be properly blamed if they fail to do so, it is reasonable to claim that doctors have a special moral obligation of beneficence to their patients. Thus (a) understood as a substantive claim about the moral obligation of doctors seems to survive Downie's counterarguments.

In response to (b) which claimed that the special obligation of beneficence which doctors owe their patients is 'at least in part altruistic' Downie claims that it is either trivially true or 'plain false'. It is trivially true if all it means is that part of the doctor's job is to benefit patients, for 'that is simply a job description, just as it is trivially true that a pilot benefits his passengers by transporting them safely'. However, if it is accepted as proposed above that it is part of the job description of being a doctor that doctors ought to act with the intention and reasonable expectation of benefiting their patients then the job description is in no way trivial. On the contrary it seems of considerable moral importance.

Once again the argument turns on the difference in job description between those occupational groups who are morally obliged to act with the intention and reasonable expectation of benefiting their clients and those who are not. Far from pilots offering a counter example to this claim, they seem to support it for there is no moral (or any other) obligation on a pilot to concern himself with the question whether or not flying his passengers safely to their destination can be reasonably expected to benefit each of them. All the pilot need concern himself with are the normal moral obligations we owe each other, as indicated above. Whether or not the result of his action (of transporting his passengers safely) can reasonably be expected to result in benefit, harm, or perhaps even disaster, for some of his passengers need be of no concern to the pilot. Indeed far from there being any professional obligation to concern themselves with the reasonably anticipated outcome for their clients of their actions, pilots would seem quite likely to be relieved of their jobs (or at least sent to the airline's psychiatrist) if they started asking their passengers why they wanted to travel to their destinations, what were the pros and cons of such a journey, and in some cases refusing to fly particular passengers because they believed (contrary to the passenger's belief) that to do so would be too harmful to the passenger. Thus pilots do not have a special moral obligation to act with the intention and reasonable expectation of benefiting their clients though once again as with most occupations it may well be true that as a matter of fact most people who get what they want (for example to fly from a to b or to buy a lump of meat or to have a piece of typing done) can be expected to benefit from having their desires fulfilled. The point is that it is not morally required - indeed it is usually none of the business - of most occupational groups even to enquire of particular clients whether or not what they desire can be reasonably expected to benefit them, let alone to withhold the goods or services if they believe that this would not be the case. It is morally required of some occupational groups, including doctors, and that requirement is in no sense morally trivial.

The second part of Downie's rebuttal of (b) is to argue that if the claim is intended to be substantial rather than trivial, 'suggesting that doctors (or pilots) show the special moral virtue of altruism in benefiting their patients or passengers' then it is 'plain false' . . . . 'Whatever they show it cannot be the moral virtue of altruism or benevolence since both doctors and pilots receive a high remuneration for so doing'. The claim in (b) is indeed morally substantive (in relation to doctors, not pilots) but it is important to be clear that by 'altruistic' is simply meant 'for the benefit of others'. Thus it was argued that the special professional obligation of doctors to benefit their patients medically 'is at least in part altruistic in that it is self-imposed by the medical profession not to benefit themselves but to benefit their patients . . .'(1). It is important not to make too much of this term 'altruistic' which simply means 'regard for others, as a principle of action; opp to egoism or selfishness' (2). However, understood thus there can surely be little doubt that the medical profession has obligations to its patients which are 'at least in part altruistic'.

Downie says that 'it cannot be the moral virtue of altruism' that doctors have since they 'receive a high remuneration' - but that is surely a non sequitur. Of course if the claim had been that it was only altruism (regard for others as a principle of action) which motivated doctors, then the claim would have been false. It seems a matter of common sense that no group of people do or even could act solely from regard for others, and of common experience that love of money is usually associated with love of self and that highly paid groups are likely to be influenced to some extent by love of money (or at least considerable appreciation thereof). But the original claim was not so naive - of course part of the medical profession's motivation is 
self-interest and desire for money. The claim defended in (b) is simply that part of their motivation, both collectively and individually, is altruistic, in that it is based on 'regard for others as a principle of action'. The importance of this collectively imposed and individually accepted altruism is precisely that it is intended to act as a counterpoise to the selfishness that doctors, like everyone else, are also motivated by.

An example may illustrate the point. It is generally in the self-interests of shopkeepers and pilots (and many other groups) to persuade their clients to buy as much of their products or services as possible. There is no special moral obligation in these occupational groups to desist from such persuasion in order to benefit the client: though they have all the normal moral obligations indicated above as a counterbalance to selfishness, there is no additional special obligation to act in ways that can reasonably be expected to benefit their clients. Thus provided the normal moral obligations indicated above are fulfilled, if a client can be persuaded to buy their products or services - let alone if the client wants to do so without any persuasion - then there is no moral obligation restraining the shopkeeper or pilot from selling his wares or services.

That there is precisely such an obligation in the case of doctors is the central claim in (a) and (b). Thus in some circumstances it might well be in the selfinterests of surgeons to perform operations that are unlikely to benefit their patients, but which the patients wanted, (with or without persuasion), just as it might very well be in the self-interests of physicians to undertake long courses of remunerative but probably non-beneficial treatments for patients who for one reason or another wanted them. However, as members of the medical profession they are under a moral obligation (beneficence to their patients) not to treat their patients unless they have a reasonable expectation that such treatment will benefit those patients. It is true that sometimes - especially perhaps in private medical practice - there is reasonable grounds for suspicion that individual doctors transgress this moral obligation and treat when they have no reasonable expectation of benefit for the patient, in order to line their pockets. The fact that within and outwith the profession people tend to be outraged when such instances are uncovered surely affords further evidence that the medical profession is recognised by its members and the public alike to have a special obligation of beneficence to its patients - an obligation which they are morally required to fulfil. It is a further issue, also raised by Downie, whether members of the medical profession are widely recognised or 'expected' to live up to their special obligation of beneficence, but that they are widely recognised to have that special obligation to act for the benefit of their patients seems inescapable. Thus (b) too seems to survive Downie's counterarguments.
Professor Downie rejects the third claim (c) - that doctors' duty of beneficence to their patients 'is at least in part supererogatory' - on the grounds that while individual doctors may in various ways behave exceptionally well, supererogation cannot be built into the concept of a doctor - cannot be considered 'a characteristic of the role of doctor as such'. Again it is important not to make too much of the term 'supererogatory' which in the original editorial was implicitly defined as an obligation 'that goes beyond what is required of every person and every occupation' (1). The moral duty of doctors to act with the intention and reasonable expection of benefiting their patients has since Hippocratic times been self-imposed by the medical profession in addition to the normal duties we all have to benefit each other, and in addition to any duties we all may or may not have to benefit the sick. In $\vec{N}$

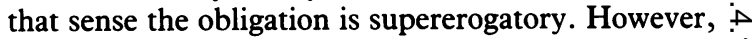
once the obligation has been accepted - and it is $\vec{v}$ claimed that acceptance of that obligation is part of what it is to be a doctor - then of course the obligation is no longer supererogatory for doctors, in the sense that for a doctor to fulfil that obligation is in no way for him to go beyond what is morally required of doctors. But, as illustrated above, it remains supererogatory in the sense that it requires doctors to go beyond the normal moral obligations we all have to benefit each other by $\vec{\oplus}$ virtue of being 'members one of another'. Thus (c) tog ळ seems to have survived.

In response to Professor Downie's final paragraph may be worth reverting to a distinction made in ant earlier editorial in these pages (3). This differentiated two concepts of 'medical ethics', the traditional one, $\frac{\circ}{\mathbb{D}}$ best summarised as 'the obligations of a moral nature $\varrho$ which govern the practice of medicine'; and $\overline{\bar{O}}$ philosophical or critical medical ethics which requires $\exists$ critical analysis of medico-moral issues, including the claims of traditional medical ethics. Sometimes philosophical medical ethics will tend to undermine $\overline{\bar{z}}$

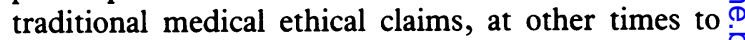
strengthen them. In the case of the fundamental Hippocratic principle of medical beneficence critical medical ethics seems - pace Professor Downie - to have reinforced rather than undermined it. Undoubtedly however, Downie's vigorous philosophical criticism has also served - at least for this writer - to clarify many of the issues involved.

\section{References}

(1) Gillon R. More on professional ethics [editorial]. Fournal of medical ethics 1986; 12: 59-60.

(2) Onions C T, ed. The shorter Oxford English dictionary. Oxford: Clarendon Press, 1965.

(3) Anonymous. Two concepts of medical ethics [editorial]. Fournal of medical ethics 1985; 11: 13. 